\title{
Incisional Vacuum-Assisted Closure Therapy
}

National Cancer Institute

\section{Source}

National Cancer Institute. Incisional Vacuum-Assisted Closure Therapy. NCI Thesaurus.

Code C157054.

A type of postoperative wound therapy that uses a dressing composed of a nonadhesive dressing, sponge, and vacuum tubing, all covered with an adhesive, nonpermeable material. Suction is applied through the tube. This system results in a decreased need for dressing changes during the immediate postoperative period and a cleaner wound environment. 